\title{
Histopathological Assessment of Orchidectomy Specimens in a Tertiary Care Center
}

\author{
Dr. Ali Abdul Latheef ${ }^{1}$, Dr. Ramdas Nayak ${ }^{2}$, Dr. Taqiya Nuzhath ${ }^{3}$, Dr Priyanka P. Shetty ${ }^{1}$, \\ Dr. Vineeth G Nair ${ }^{4}$ \\ ${ }^{1}$ Junior Resident, Department of Pathology, Yenepoya Medical College, Mangaluru, India \\ ${ }^{2}$ Professor and HOD of Department of Pathology, Yenepoya Medical College, Mangaluru, India \\ ${ }^{3}$ Assistant Professor Department of Pathology, Kanachur Medical College, Mangaluru, India \\ ${ }^{4}$ Pathologist, Suburban Diagnostics, North Goa, India
}

*Corresponding author - Dr. Ali Abdul Latheef, pathworld58@ gmail.com

Received 15 January 2019;

Accepted 28 February 2019;

Published 01 March 2019

\begin{abstract}
Introduction: Orchidectomy is a medical procedure to remove one or both testicles in males. The testis can be removed for torsion/infarction,infection,therapeutic castration for prostate cancer,cryptorchidism and tumor.In our study we did a histomorphological study these lesions which is a rare surgery other than therapeutic purpose. Aims \& Objectives: The aim of our study was to emphasise the clinical, radiological and histomorphological features of the rare orchiectomy procedure in various conditions of testis and to find out the clinical relevance. Materials \& Methods: This was a retrospective and prospective analysis done for 18 months (January 2016-June 2017). All orchidectomy specimens received in the Department of Pathology were analyzed with respect to clinical indications,radiology,morphology and microscopic features. Results: Out of a total of 23 orchidectomy cases 16 were unilateral and 7 bilateral.Most common age group was 50 to 70 years(13). The youngest and eldest patients were $6 \& 89$ years respectively. The most common etiology was therapeutic(7 cases of carcinoma prostate ), torsion in 6,epididymo-orchitis in 3, benign tumours in 2,inflammtory causes in 3 and one case of cryptorchidism. Conclusion: Our study helped us to assess and evaluate the clinical relevance of orchidectomy by histomorphological study of these lesions and to defer the procedure in certain non-tumoral cases for the benefit of the patient.
\end{abstract}

Keywords: Orchidectomy, Torsion, Leiomyoma, Adenomatoid, Histomorphology.

\section{Introduction}

The testes are paired male reproductive glands (gonads) located in the scrotum suspended by the spermatic cord, with an average weight of approximately $15-19 \mathrm{~g}$ each. The right testis is usually bigger than the left. These reproductive glands produce sperm and the male sex hormone testosterone which is responsible for the secondary sexual characteristics of the male. Few males are born with only single testis and some get surgical removal for underlying testicular pathology. ${ }^{[1,2]}$

An orchidectomy is a medical procedure to remove one or both testes in males. The testis may be removed for torsion/infarction, infection, therapeutic castration for prostate cancer, cryptorchidism and tumour.3 In this study, histo-morphological assessments of orchidectomy specimens were done.

\section{Aims \& Objectives}

The aim of this study was to identify the different types of orchidectomy specimens and indication for which the procedure was performed, and to identify general histological features of each type.

\section{Materials \& Methods}

This was a prospective study done for a period of 18 months (January 2016 - June 2017). Twenty-three orchidectomy specimens received in the Department of Pathology, Yenepoya Medical College, during the above-mentioned time period were included.

All cases were received with adequate clinical history. The specimens were kept for fixation overnight and grossed the next day. Hematoxylin and eosin (H\&E) stained slides of formalin-fixed paraffin-embedded blocks were evaluated by two pathologists using light microscopy without any prior knowledge about the clinical features of cases. Each orchidectomy specimen consisted of at least 3 random sections of the testis. 


\section{Results}

Out of a total of 23 orchidectomy cases, 16 were unilateral and 7 were bilateral orchidectomies. The most common age group was between 50 to 70 years $(n=13)$ (Figure 1). The youngest and eldest patients were $6 \& 89$ years old respectively. The most common indication for orchidectomy was therapeutic (Figure 2). Of 23 cases, 7 cases $(30.4 \%)$ were performed as part of treatment for carcinoma of prostate and the majority of these specimens showed normal testicular histology. Torsion in $6(26.1 \%)$ cases showed hemorrhagic infarction and coagulative necrosis of seminiferous tubules with interstitial hemorrhage (Figure 3B). There were 3 $(13 \%)$ cases of atrophic testis which showed atrophic seminiferous tubules lined by germ cells and spermatogonia with a complete absence of spermatid and spermatozoa and focal areas of Leydig cell hyperplasia. Two (8.7\%) cases of benign tumors comprising of a leiomyoma which showed tumour cells arranged in loose fascicles of spindle cells with vesicular uniform nuclei in a hyalinized stroma (Figure: 4B). One case of adenomatoid tumour with part of testis and paratesticular tissue showed a tumor composed of predominantly cords, tubules, small glands and occasional angiomatoid pattern (Figure 5).

There were 3 (13\%) orchidectomy specimens removed for inflammatory causes in which two cases were reported as granulomatous orchitis (Figure 6) and one case of testicular abscess. One (4.4\%) case of hematocele showed a thickened cyst wall with areas of hyalinization, calcification, and the lumen showed necrotic material, foamy macrophage, giant cell reaction and cholesterol clefts, the adjacent areas showed features of atrophic testis. One $(4.4 \%)$ case of cryptorchidism with testis showed atrophic seminiferous tubules with decreased germ cell number, focal Leydig cell hyperplasia, interstitial fibrosis and sclerosis, the spermatic cord showed atrophic ductules.

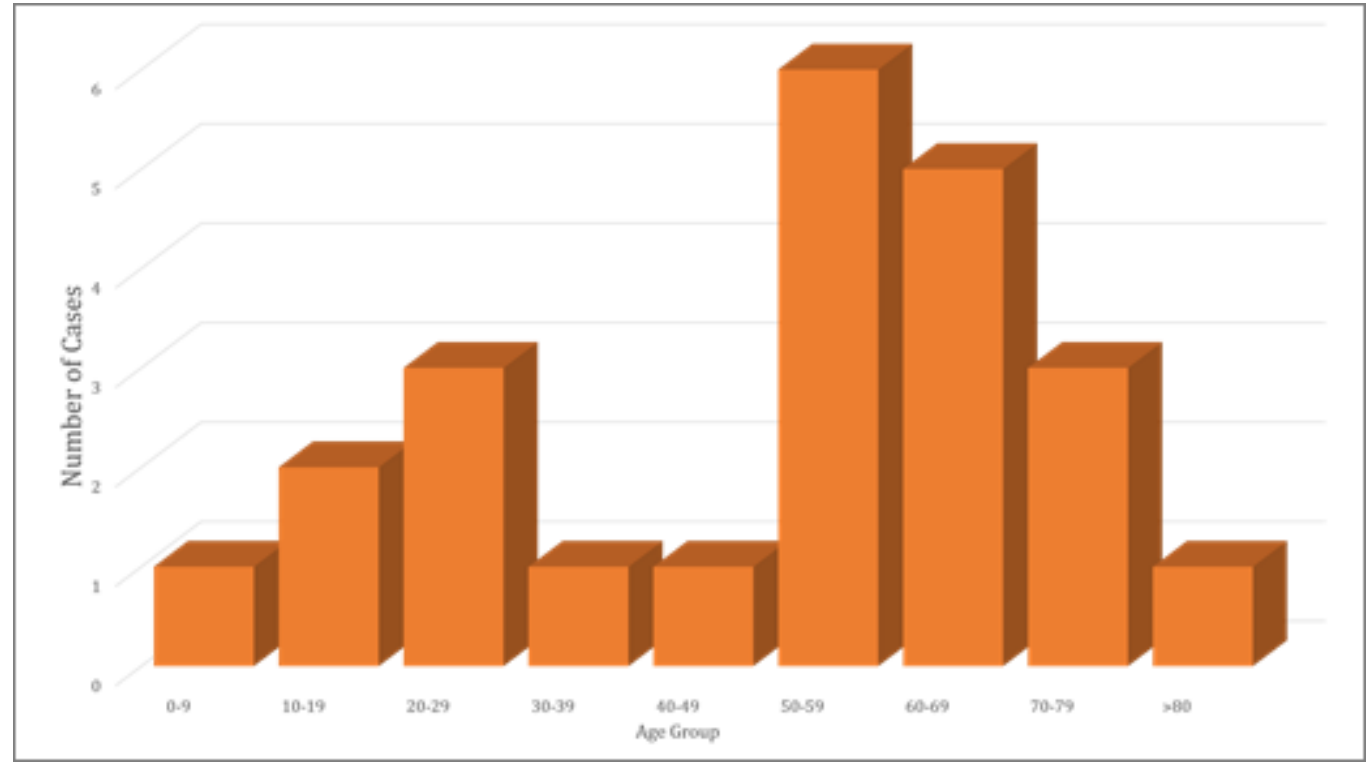

Figure 1: Age Distribution

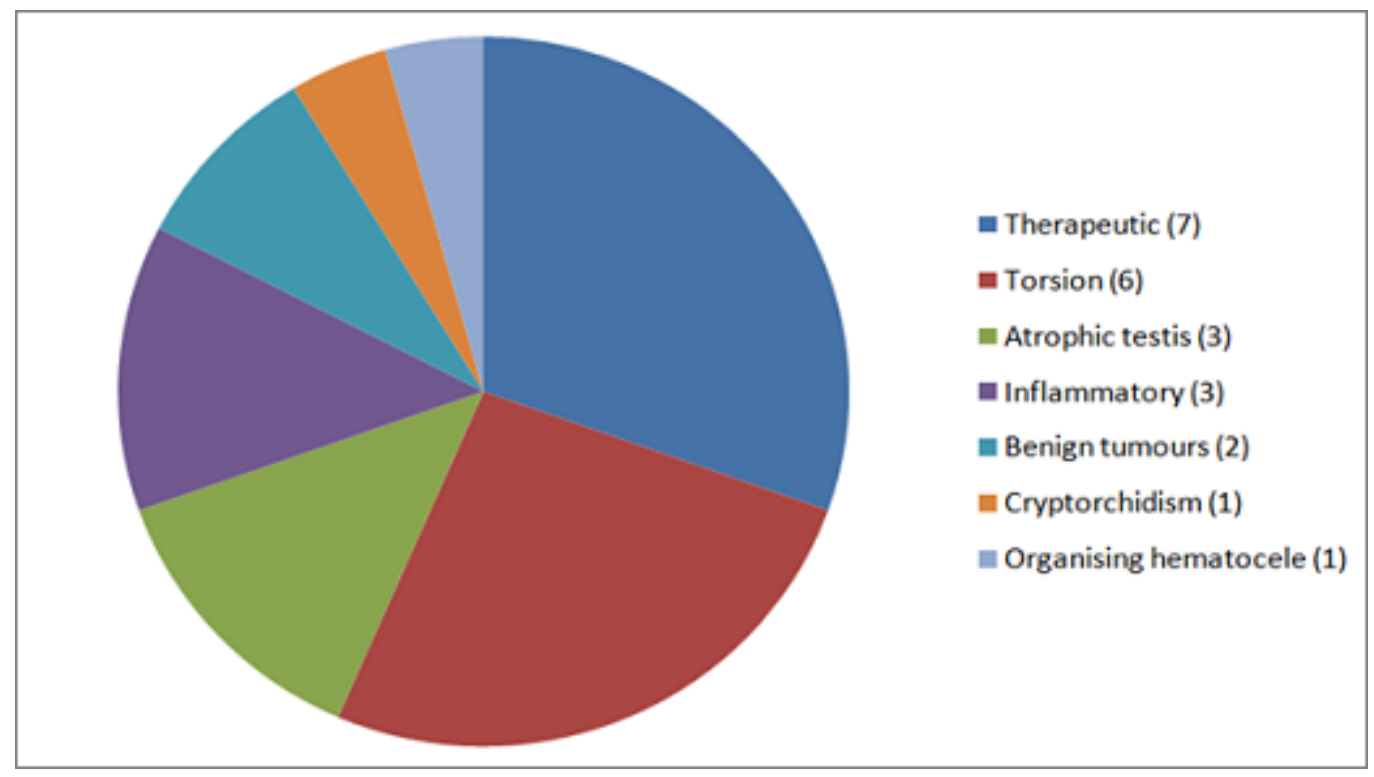

Figure 2: Indications of Orchidectomy 


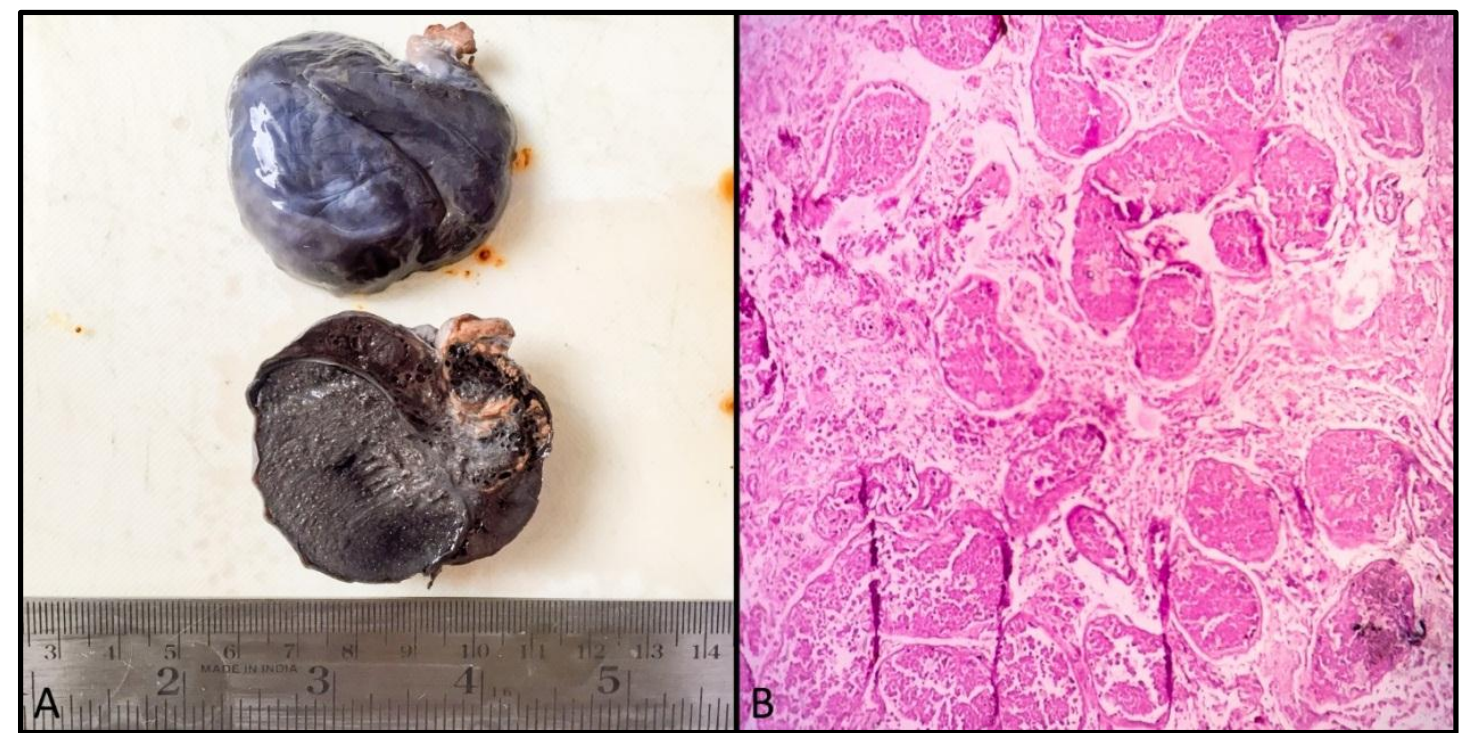

Figure 3: (A) Gross - Torsion Testis; (B) Photomicrograph showing infarcted testicular tissue (H\&E, 10x)

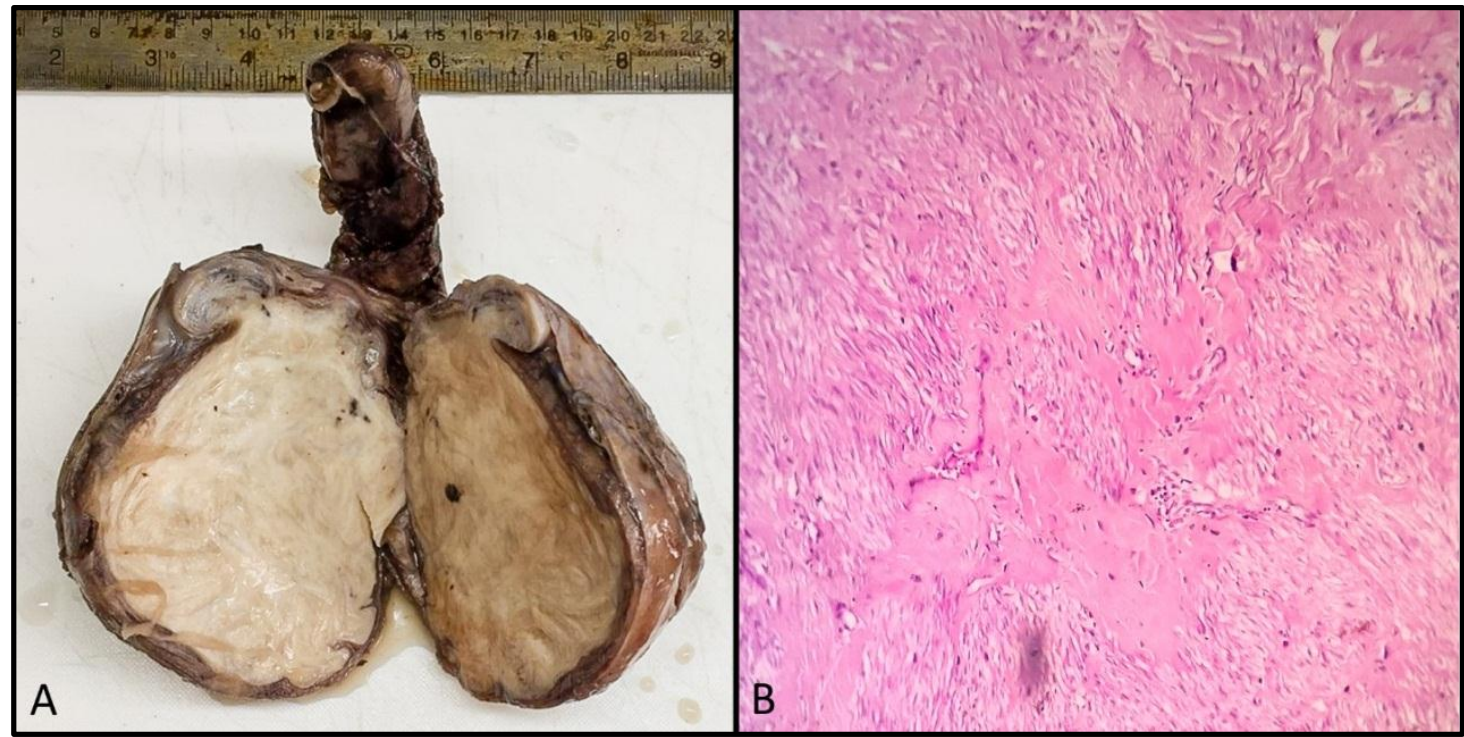

Figure 4: (A) Gross - Leiomyoma Testis; (B) Photomicrograph of the Leiomyoma (H\&E, 10x)

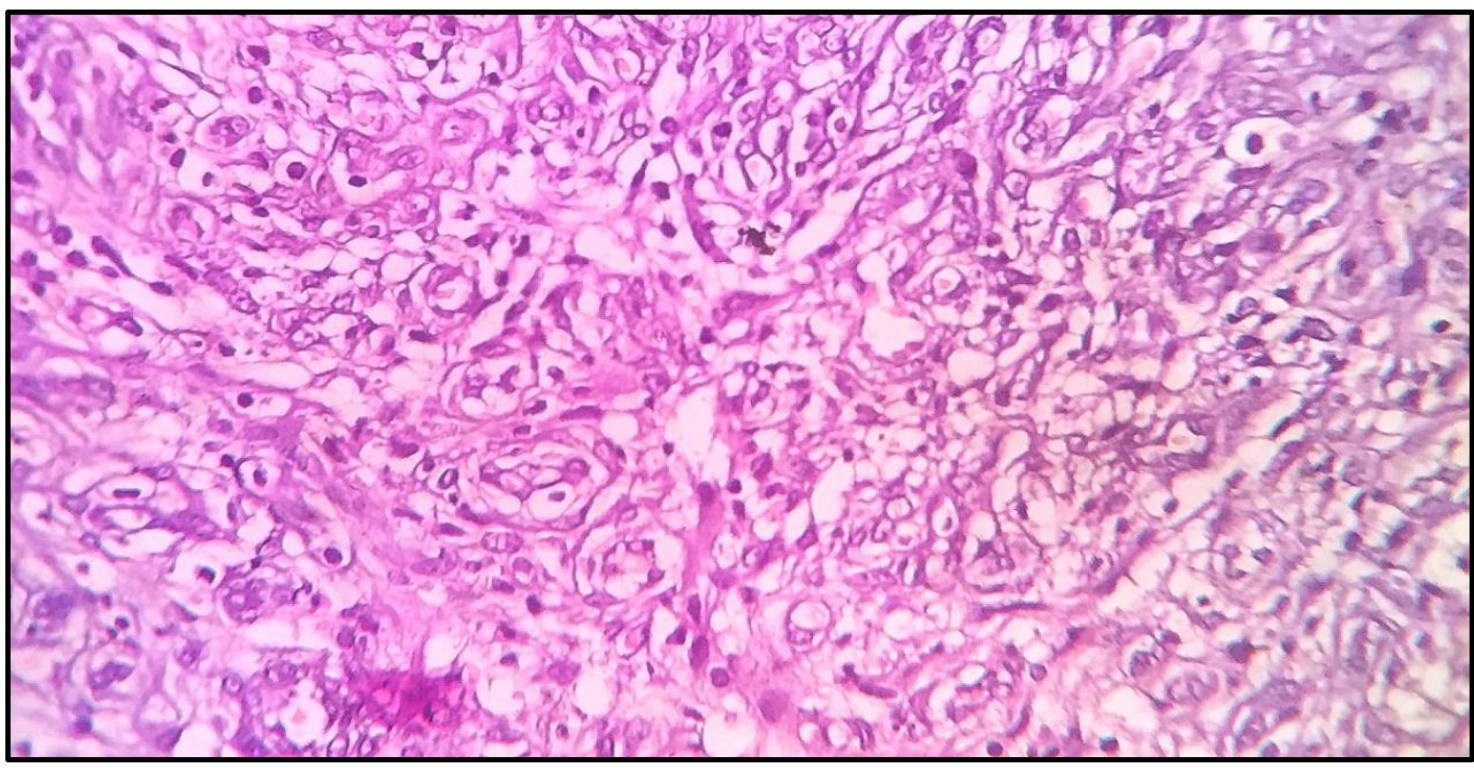

Figure 5: Photomicrograph of paratesticular adenomatoid tumour composed predominantly cords, tubules and small glands (H\&E,40x) 


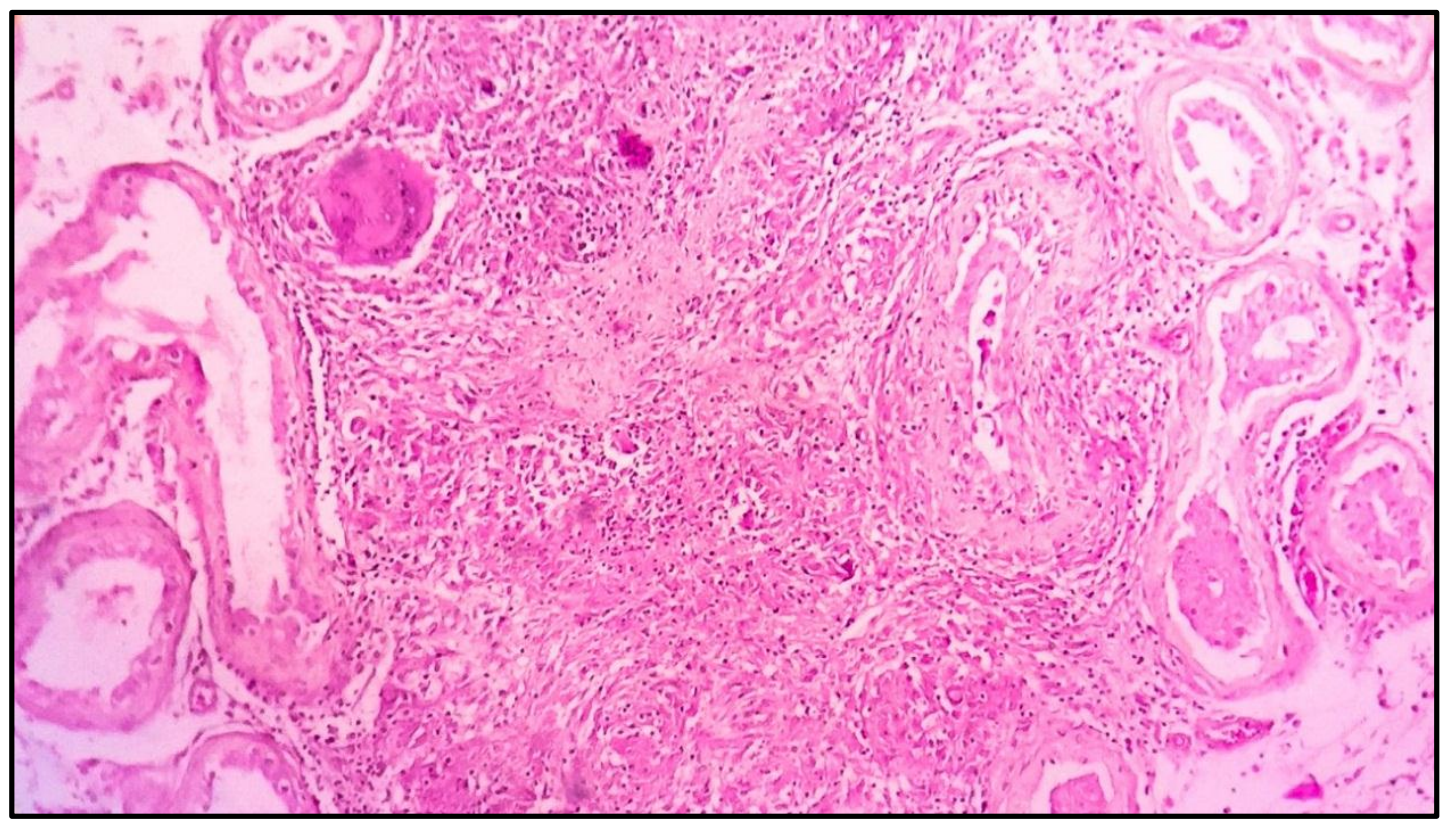

Figure 6: Photomicrograph of testicular tissue showing Tuberculous granulomas $(\mathrm{H \& E}, 10 \mathrm{x})$

\section{Discussion}

In this study, the most common indication for orchidectomy was found to be therapeutic castration for carcinoma prostate (52\%). Most prostate carcinomas are hormone-dependent; this means that they require testosterone for disease progression. Ninety per cent of testosterone is synthesized by Leydig cells of the testis, whereas $5 \%$ is formed by adrenal glands. ${ }^{[4]}$ Bilateral orchidectomy is the simplest way of hormonal blockade, a procedure described by Huggins \& Hodges. ${ }^{[5]}$ Bilateral subcapsular orchiectomy is an inexpensive and successful modality of treatment for advanced prostate cancer. Its acceptance is fairly good and its psychological effects are almost non-existent. ${ }^{[4]}$

A study done by Olapade-Olaopa et al (2011) on 142 patients with histologically diagnosed prostate cancer had bilateral orchidectomy in which two specimens had evidence of testicular metastases while 106 showed evidence of testicular atrophy and 34 of the specimens were reported as normal testes. ${ }^{[6]}$ In this study, all the 7 cases $(30.4 \%)$ done for therapeutic purpose were revealed normal testicular histology.

Testicular torsion (TT) is a severe acute urological emergency which is caused by distortion of the spermatic cord. It needs timely diagnosis and treatment. Unfortunately, its significance is still undervalued in everyday life: early-detected TT can be cured in almost every case, whereas delayed detection may lead to loss of the testis. There are two peaks of frequency: perinatally and in pubertal life. Even so, TT is not excluded in adults or elderly patients. It requires immediate recognition and therapy. It is generally agreed that irreversible changes will begin after $6 \mathrm{hr}$ or after only $4 \mathrm{hr}$ in the event of an extremely twisted spermatic cord. Thus, time is the most significant factor in the emergency care of TT, the recovery rate and late outcome typically depend on this. The success of surgery within 4-8 hr from the onset of the symptoms is around $90 \%$ to $100 \%$, but at $12 \mathrm{hr}$ it is $50 \%$ and after 1 day only $10 \%$. Delay can be fatal and may lead to impaired fertility and loss of the testis. ${ }^{[7]}$ Sessions et al (2003), conducted a retrospective assessment of 186 boys with TT who underwent surgical exploration. Of which, $52 \%$ had developed torsion in the left testis and $48 \%$ in the right testis. ${ }^{[8]}$ In our study, we found equal distribution in both left and right testis.
Genital tuberculosis is usually a disease of sexually active males and occurs most frequently between the ages of 20 and 50 years, although it has been reported in children also. The prostate, epididymis and seminal vesicles are the most frequently affected location while involvement of the testis is very rare and found at autopsy in only $3 \%$ of the patients with genital tuberculosis in chemotherapy era study. A study done by Shah H et al (2004) on bilateral epididymitis with right-sided orchitis and scrotal involvement in a young patient with infertility was diagnosed as tuberculosis. ${ }^{[9]}$ Paul J et al (2010) have reported a case of 55-yearold male with unilateral testicular swelling of four months duration which was diagnosed as tuberculosis. ${ }^{[10]}$ In our study, two cases of testicular swelling were reported and both the cases were seen as unilateral testicular swelling. In this study, of the two cases, one was granulomatous orchitis and other showed features of tuberculosis.

Adenomatoid tumors (AT) are rare, benign tumors of the male and female genital tract. They are also known by the pseudonym of "benign mesothelioma" of the intrascrotal tumors but they usually present as extra testicular masses. They are the most common paratesticular neoplasm and account for about 30\% of all paratesticular masses. On gross morphology these tumours are usually small, solid, firm, greyish white to tan and poorly to wellcircumscribed masses. Histopathologically, these tumours show adenoid or tubular glandular, angiomatoid, solid, cystic or transitional pattern. Vacuolated cytoplasm with cytologic atypia of the cells is the pathognomic feature of these tumours. In the majority of the lesions, the stroma is fibrous but a smooth muscle component is also noted. They are unencapsulated due to which their pattern of growth is not distinctive of benign neoplasms and frequently occupy the surrounding tissue.$^{[11-13]}$ In the present study, we observed a tumour composed of predominantly cords, tubules, small glands and occasional angiomatoid pattern. A case report done by Sameer et al (2016) and a study was done by Amin W et al (2009) on Intratesticular adenomatoid tumour showed the age was 27 years and 36 years respectively whereas, ${ }^{[11,14]}$ in this study the age was 58 years.

Leiomyomas are benign tumours that arise from smooth muscle cells. In the urinary tract, they can develop from the renal pelvis, bladder, prostate, spermatic cord, epididymis, glans penis or the 
scrotum. Intratesticular leiomyomas are exceptionally rare. Intratesticular leiomyoma most commonly presents in the fifth decade of life and as a nontender scrotal swelling. Grossly, these tumours are seen to be well defined, with a whorled appearance on cut-section. On microscopy, they are seen to be well-circumscribed lesions composed of interlacing bundles of smooth muscle cells. ${ }^{[15]}$ In the present study, we reported a case of intratesticular leiomyoma which, on gross examination, measured 10.5 x 9 x 7.5 $\mathrm{cm}$ and microscopically, was composed of loose fascicles of spindle cells with vesicular uniform nuclei in a hyalinized stroma. These tumours are exceptionally rare.

Cryptorchidism is a pathological condition described as the failure of the testis to move down into the scrotum. It is one of the most frequent inherited anomalies happening in $1 \%$ to $4 \%$ of full-term neonates. The incidence of cryptorchidism is about $1 \%$ at 1 year of age. The treatment of cryptorchidism in infants and children is well known. Orchiopexy is a surgical intervention is suggested for undescended testis in babies of greater than 6 months of age. ${ }^{[16-18]}$ In the current study we observed a case of cryptorchidism which showed atrophic seminiferous tubules with decreased germ cell number, focal Leydig cell hyperplasia, interstitial fibrosis and sclerosis and the spermatic cord showed atrophic ductules.

\section{Conclusion}

A wide variety of indications are seen for performing orchidectomy and in our study, we found that therapeutic castration for carcinoma prostate was the most common. The gold standard for diagnosis is histopathological examination and a detailed knowledge of the spectrum and frequency of the various conditions that can lead to orchidectomy is essential for devising protocols and newer modalities of treatment which may replace this procedure in the future. Our study is limited by the time frame and geographical constraints and, as such, a more detailed population level study, over a longer period is warranted for a broader and definitive understanding of the causes, clinical features and histological presentation of the conditions which lead to orchidectomy. Such information can lead to development or improvement of protocols so as to reduce the number of these highly invasive and psychologically traumatic procedures.

\section{References}

[1] Mills, S. Histology for pathologists.4th ed. Philadelphia,PA 19103 USA: Lippincott - Raven; (2012).

[2] Mills, S. Greenson, J, Hornick, J, Longacre, T. and Reuter, V. Sternberg's diagnostic surgical pathology. 6th ed. Philadelphia, PA: Lippincott Williams et Wilkins; 2015.

[3] Oranusi CK, Onyiaorah IV, Ukah CO. Pattern of testicular biopies as seen in a tertiary institution in nnewi, southeast Nigeria. Niger J Surg. 2014;20(2):55-8.
[4] Paula, A. Piccelli, H. Pinto, N. Teles, A. Franqueiro, A. Maltez, A. and Silva, J. Economical impact of orchiectomy for advanced prostate cancer. International braz j urol, (2003);29(2): pp.127-132.

[5] Huggins C, Hodges CV. Studies on prostatic cancer: the effect of castration of estrogen and of androgen injection on serum phosphatases in metastatic carcinoma of the prostate. Cancer Res. 1941; 1: 293-7.

[6] Olapade-Olaopa et al. Histology of orchidectomy specimens in Nigerian patients with prostate cancer. Infectious Agents and Cancer. 2011; 6(Suppl 1):A3.

[7] Fehér, Á. and Bajory, Z. A review of main controversial aspects of acute testicular torsion. Journal of Acute Disease. (2016); 5(1), pp.1-8.

[8] Sessions AE, Rabinowitz R, Hulbert WC, Goldstein MM, Mevorach RA. Testicular torsion: direction, degree, duration and disinformation. J Urol. 2003; 169(2): 663-5.

[9] Shah, H., Shah, K., Dixit, R. and Shah, K. Isolated tuberculous epididymo-orchitis. Indian J Tuberc. (2004); 51, pp.159-162.

[10] Paul J, Krishnamoorthy S, Teresa M, Kumar S. Isolated tuberculous orchitis: A mimicker of testicular malignancy. Indian J Urol. 2010; 26(2):284-6.

[11] Amin, Waqas and Anil V Parwani. "Adenomatoid tumor of testis" Clinical medicine. Pathology vol. 2009; 2 1722.

[12] Delahunt B, Eble JN, King D, Bethwaite PB, Nacey JN, Thornton A. Immunohistochemical evidence for mesothelial origin of paratesticular adenomatoid tumour. Histopathology. 2000; 36(2):109-15.

[13] Eble JN SG, Epstein JI, Sesterhenn IA. World Health Organization Classifcation of Tumors. Pathology and Genetics of Tumour of the Urinary System: IACR Press; Lyon 2004

[14] Al Diffalha, S., Pambuccian, S., Farooq, A. and Barkan, G. Intratesticular adenomatoid tumor: A case report and review of the literature. Human Pathology: Case Reports, (2016): 4, pp.13-17.

[15] Yong ZP, Liu ZB, Chau C, Chong KT. A rare case of intratesticular leiomyoma. Singapore Med J. 2015;56(9):e145-6.

[16] Jeong, S., Lee, S., Ku, J. and Lee, S. Clinical Characteristics and Treatment of Cryptorchidism in Adults: A Single Center Experience. The World Journal of Men's Health. (2014);32(2), p.110.

[17] Sijstermans K, Hack WW, Meijer RW, van der VoortDoedens LM. The frequency of undescended testis frombirth to adulthood: a review. Int J Androl.2008;31:111.

[18] Moradi M, Karimian B, Moradi A. Adult orchidopexy: a survey on necessity of intraoperative testicular biopsy. NephroUrol Mon 2011;3:196-200. 